DOI: $10.5216 /$ racs.v4.59301

\title{
A dinâmica Panhi dos temas contextuais
}

Sheila Baxy Pereira de Castro Apinajé ${ }^{1}$

\section{RESUMO}

Este texto busca apresentar alguns estágios docência (1, 2 e 3), realizados na Escola Estadual Indígena Tekator, aldeia Mariazinha e na Escola Estadual Indígena Pepkror, aldeia Boutica, Território Apinajé. Estas atividades têm relação direta com a proposta do Núcleo Takinahaky de Formação Superior Indígena (NTFSI), que busca se apropriar e experimentar o uso dos temas contextuais (TC) para uma reformulação radical de nossas matrizes curriculares colonialistas. Foco-me em mostrar como a problematização é fundamental para o desenvolvimento dos TCs, como a articulação entre atividades de problematização, atividades práticas e atividades comunitárias potencializam as aulas e como, claramente, passo a compreender melhor, ao longo dos estágios, a importância do fluxo de tempo para a prática de um saber transdisciplinar.

PALAVRAS-CHAVE: Temas contextuais. Decolonialidade. Interculturalidade.

\section{La dinámica Panhi de los temas contextuales}

\section{RESUMEN}

Este texto busca presentar algunas etapas docencia (etapa 1, 2 y 3), realizados en la Escuela Tekator, aldea Mariazinha y en la Escuela Amxàk, pueblo Boutica, Territorio Apinajé. Estas actividades tienen relación directa con la propuesta del Núcleo Takinahaky de Formación Superior Indígena, que busca apropiarse y experimentar el uso de los temas contextuales para una reformulación radical de nuestras matrices curriculares colonialistas. En mi opinión, como la problematización es fundamental para el desarrollo de los TC y cómo, claramente, paso a comprender mejor, a lo largo de las etapas, la importancia del flujo de tiempo para la práctica de un saber transdisciplinario.

PALABRAS ClAVE: Temas contextuales. Decolonialidad. Interculturalidad.

\footnotetext{
${ }^{1}$ Graduanda do Curso de Licenciatura em Educação Intercultural do Núcleo Takinahakỹ de Formação Superior Indígena (NTFSI) da Universidade Federal de Goiás (UFG). Professora Apinajé. Aldeia Botica, Tocantinópolis, TO, Brasil.. E-mail: articulandoeconstruindosaberes@gmail.com.
} 


\section{Introdução}

As atividades pedagógicas aqui apresentadas foram realizadas na Terra Indígena Apinajé, localizada no norte do Estado do Tocantins. Trata-se de território demarcado e homologado, cuja língua falada é o Panhi Kaper (Apinajé). Estamos próximos aos municípios de Tocantinópolis, Maurilândia, Nazaré, Luzinópolis e São Bento.

Em nosso território, possuímos 54 aldeias, com duas sedes principais: a Aldeia Mariazinha e a Aldeia São José.

As atividades foram realizadas por meio de pesquisa, anotações em caderno e observação de alguns professores indígenas nas aldeias e, também, de missionários que alfabetizavam na língua materna.

Utilizei, sobretudo, o método do tema contextual (TC), buscando problematizar nossa realidade, tomando como base, práticas de sustentabilidade territorial e a epistemologia Panhi (indígena). Aprendi sobre os TCs no Curso em Educação Intercultural da Universidade Federal de Goiás (UFG), que forma alunos indígenas em nível superior.

Muitos egressos Apinajé estão preocupados em formar os próprios sabedores da cultura indígena, para nós mesmos escrevermos a nossa cultura de subsistência, de milhões de anos. E mostrar para o povo não indígena que nós somos povo da floresta, temos saberes conectados com tudo que está dentro do território, como a terra e o céu.

Queremos reconstruir a nossa própria política de educação escolar que não seja fragmentada da nossa cultura.

\section{Estágio I}

Meu primeiro estágio docência foi sobre a alfabetização. Procurei informações bem específicas sobre as letras e os sons das palavras. Foi muito difícil, pois algumas letras não correspondem com os sons falados na aldeia.

Os professores indígenas relataram que é muito difícil alfabetizar, pois há muitas vogais e as consoantes confundem para formar as palavras. Tem que observar muito para poder escrever. Atualmente, já foi realizada revisão de muitas palavras.

As crianças só podem entrar para estudar quando estiverem na idade certa, exigida pela Secretaria de Educação (SEDUC-TO). 
Nós, indígenas, pensamos que é preciso aprender as duas formas de escrita: na língua materna e no português. Às vezes, não sai alfabetizado nem na língua portuguesa nem na língua materna.

Os professores opinam que para alfabetizar de $1^{\mathrm{o}}$ ao $4^{\mathrm{o}}$ ano do ensino fundamental deve ser só na língua materna e não ter interferência de disciplina nem de português. A criança não tem domínio de outras disciplinas, e tem poucos materiais pedagógicos próprios na escola.

Os missionários falaram como faziam na sala de aula para alfabetizar os adolescentes e adultos, na década de 70, 80 e 90. Os missionários aprendiam a língua Apinajé e confeccionavam o material pedagógico. Hoje, grande parte desses materiais é usado nas salas de aula pelos professores indígenas, como por exemplo, as cartilhas 1, 2, 3, 4 e 5 . O missionário Renato alfabetizava somente na língua materna e os alunos aprendiam a ler e a escrever na sua própria língua materna. Não tinha interferência de outras disciplinas e o aluno ficava no seu próprio lugar aprendendo tudo que estava conectado com a natureza. Muitos aprenderam a escrever somente na língua materna e não sabem ler em português.

Após minha pesquisa, vi que é muito importante trabalhar em sala de aula com o tema contextual. Tive muitas ideias para praticar as novas práticas pedagógicas. Pensei e agi conforme o levantamento pesquisado. Produzi o estágio para valorizar e fortalecer a escrita e estimular a comunidade indígena a atualizar suas culturas particulares através da escola. Penso que temos que registrar o novo tempo.

Tudo que foi pesquisado foi para o planejamento das aulas. Cada passo do tema contextual, como desenvolvi o tema contextual nas turmas do $5^{\circ}$ ano do ensino fundamental etc.

Fui até a Escola Tekator, conversei com o coordenador e o orientador educacional, comunicando que realizaria o estágio docência supervisionado. Fiquei surpresa quando eles me comunicaram que eu não podia realizar o estágio, devido ao fato de trabalhar em sala de aula. Eu teria que realizar o estágio nos momentos de folga. Achei muito difícil esta situação.

No meu primeiro estágio, o tema contextual foi ministrado na dinâmica de uma matriz curricular disciplinar, 50 minutos por aula, em dias alternados. Isto não foi bom, como vim a perceber. Conversei com o professor de turma do $5^{\circ}$ ano e ele me autorizou a realizar o estágio nos momentos de folga, em outras salas. Chamei o coordenador pedagógico para assistir as aulas e me alegrei muito por poder dar as aulas. A professora Rosangela Gomes me ajudou. 
Foto 1 - Professora Sheila Maxy ministrando aula.

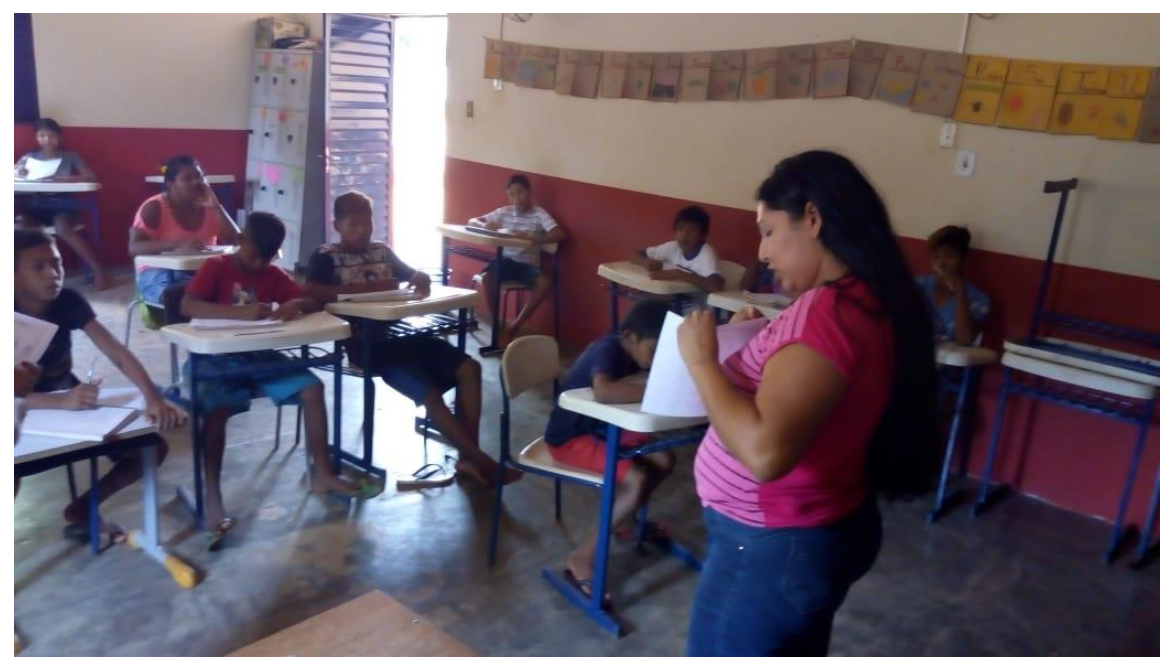

Fonte: Sheila Maxy.

Apresento resumidamente meu primeiro estágio no quadro abaixo. Ele se realizou em 5 aulas alternadas.

Quadro 1 - Resumo das atividades do Estágio 1.

\begin{tabular}{|c|l|}
\hline Atividade de Problematização - aula 1 & $\begin{array}{l}\text { Apresentei o tema para a turma. Falei da importância da } \\
\text { Universidade Federal de Goiás, do Curso de Educação } \\
\text { Intercultural, onde estudo nos períodos de férias e tenho } \\
\text { aulas presencias em Janeiro/Fevereiro e Julho/Agosto. } \\
\text { Falei da importância da nossa língua materna Apinajé, } \\
\text { pois na nossa linguagem temos os cânticos, comidas } \\
\text { tradicionais, festas culturais. É a partir dela que } \\
\text { garantimos a preservação do território, das águas que } \\
\text { correm dentro da área indígena. }\end{array}$ \\
\hline Atividade de & $\begin{array}{l}\text { Em grupo, apresentei a cultura da aldeia. Oralmente, } \\
\text { narrei o que ver na aldeia e na escola. Expliquei como é a } \\
\text { escrita na língua materna. }\end{array}$ \\
\hline Atividade de explicação - aula 3 & $\begin{array}{l}\text { Ensinei como escrever as vogais em Apinajé. Como } \\
\text { escrever o nome na língua materna. Concentrei-me nas } \\
\text { vogais. Fizemos exercícios. }\end{array}$ \\
\hline Atividade de explicação - aula 5 & $\begin{array}{l}\text { Ensinei como escrever as consoantes em Apinajé. Como } \\
\text { escrever o nome na língua materna. Concentrei-me nas } \\
\text { consoantes em Apinajé. Expliquei sobre as diferenças } \\
\text { entre vogais e consoantes. Fizemos exercícios. }\end{array}$ \\
\hline Realizamos a leitura do alfabeto inteiro em Apinajé.
\end{tabular}

Fonte: Sheila Maxy. 
Imagem 1 - Alfabeto Apinajé.

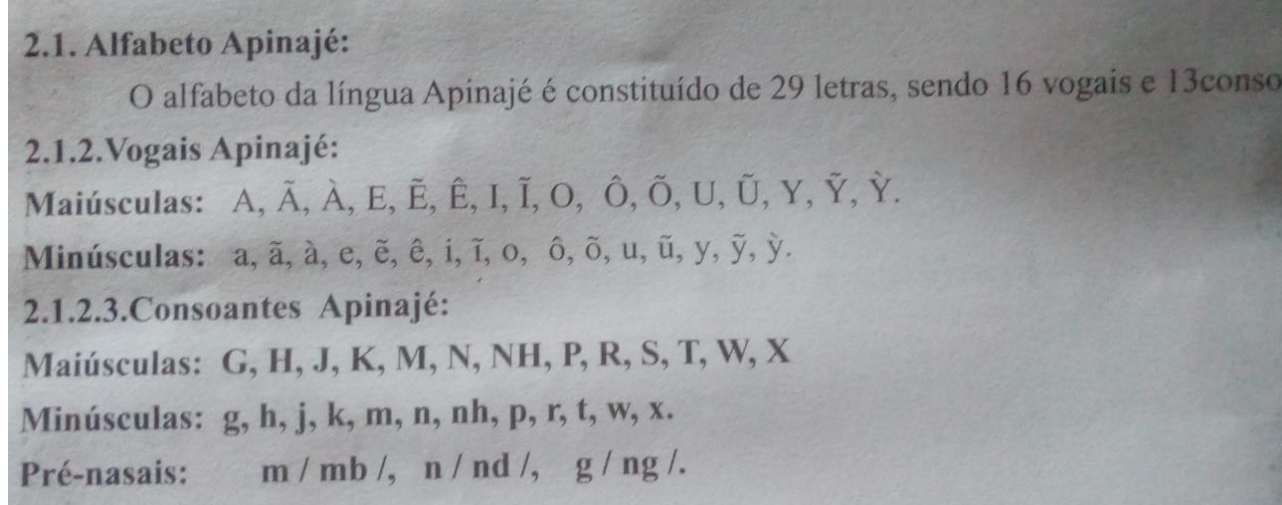

Fonte: Sheila Maxy.

\section{Estágio II}

Meu segundo estágio docência partiu de uma problematização sobre o alcoolismo. Realizei o estágio nas aldeias São José, Girassol, Riachinho e Olho d’Água. Pesquisei relatos de famílias que sofreram perdas causadas por homicídios e outras causas devido o alcoolismo na aldeia.

As famílias relataram que a bebida alcoólica é comprada nas cidades vizinhas e levada para aldeia. Quando ingerida, gera discussão e agressões físicas. A família fica preocupada. O tema foi escolhido para alertar as crianças, a comunidade e a escola sobre a situação. Busquei estimular atividades comunitárias para envolver a comunidade.

Minha pesquisa teve como base o levantamento acerca do alcoolismo e seus efeitos observados nas comunidades indígenas Apinajé. Parto de uma demanda comunitária e da preocupação com o futuro. Percebi que muitas famílias Apinajé revivem em seus diálogos seus sentimentos de tristeza, saudade e revolta.

Entendi também que a crise que vivemos tem a ver com a perseguição e luta histórica contra os não indígenas, que buscavam apropriar-se de nosso território o que trouxe, segundo dados da história, inúmeras mortes, e quase causou nossa extinção.

Busquei informação nos postos de saúde, se existem palestras sobre o alcoolismo ou mesmo algum tratamento. Li a pesquisa do Projeto Extraescolar, componente obrigatório do currículo do Núcleo Takinahaky de Formação Superior Indígena, do Professor Davi Wanhme Apinajé. Em sua pesquisa, ele trata do alcoolismo dentro da aldeia. Pesquisei também na internet. 
Organizei reuniões comunitárias nas aldeias, nas quais foi decidido pelos caciques montar barreiras na entrada das aldeias, com jovens guerreiros, para impedir a entrada da bebida alcoólica. Isso ajudou bastante.

Pedi autorização para realizar, então, atividades pedagógicas em sala de aula, debatendo com os alunos sobre o tema, como apresento resumidamente no quadro abaixo. Ainda trabalhei em aulas alternadas. Não me dava conta da importância do uso do tempo para atividades transdisciplinares.

Quadro 2 - Resumo das atividades do Estágio 2.

\begin{tabular}{|c|l|}
\hline Atividade de problematização - aula 1 & $\begin{array}{l}\text { Apresentei para os alunos os propósitos do tema } \\
\text { contextual, com palestras na sala, mostrando fotos de } \\
\text { outros povos indígenas alcoolizados. }\end{array}$ \\
Atividade de aconselhamento - aula 2 & $\begin{array}{l}\text { Aconselhei sobre o álcool e expliquei os sintomas do } \\
\text { alcoolismo. Alcoolismo é conhecido como síndrome da } \\
\text { independência do Álcool. Gera compulsão: uma } \\
\text { necessidade forte ou desejo incontrolável de beber. Os } \\
\text { sintomas de abstinência física são náusea suor, tremores, e } \\
\text { ansiedade quando para de beber. }\end{array}$ \\
\hline Atividade de debate - aula 3 & $\begin{array}{l}\text { Fiz um debate com os alunos que também fizeram seus } \\
\text { questionamentos sobre o alcoolismo. }\end{array}$ \\
\hline Atividade prática - aula 4 & $\begin{array}{l}\text { Realizamos atividades de pinturas de cores para as } \\
\text { famílias, para envolver a comunidade no tema. }\end{array}$ \\
\hline Atividade coletiva/comunitária - aula 5 & $\begin{array}{l}\text { Realizamos uma atividade de apresentação oral dos alunos } \\
\text { para outras turmas. Tratamos da habilidade da oralidade. } \\
\text { Debatemos sobre o alcoolismo que gera morte. }\end{array}$ \\
\hline
\end{tabular}

Fonte: Sheila Maxy.

\section{Estágio III}

O tema contextual de meu terceiro estágio foi debatido na comunidade da aldeia Botica. Trata-se de uma demanda comunitária. Parti da problematização de que é necessário retomarmos as relações sociais que transmitem os saberes dos adultos para as crianças. Neste caso, especificamente, percebi que a confecção de esteira e de abano não estão mais sendo ensinadas pelas avós e mães às netas e filhas.

Pesquisei com as anciãs e busquei criar atividades práticas e comunitárias para aperfeiçoar a elaboração das esteiras e dos abanos. Eu mesma sou conhecedora desta confecção. Aprendi com minha bisavó, que repassou todo o processo que foi ensinado a ela, 
por alguma ancestral mulher. Entre os Apinajé é fundamental a transmissão de conhecimentos por meio das mulheres.

Expliquei para o cacique José Ribeiro (Zé da Doca) sobre a importância do estágio docência na escola e para a comunidade da Aldeia Botica.

Criei práticas pedagógicas fora da escola. O pé de coqueiro é encontrado na mata fechada, é nativo do território Apinajé, sendo retirado da palha, o olho amarelo que fica no centro do pé do babaçu, para fazer diversas utilidades como cofo, abano, esteira, apito, cocar e outros objetos das mulheres indígenas.

Apresento resumidamente as atividades do estágio docência abaixo. É importante falar que as atividades pedagógicas foram em sequência. Sendo assim, consegui desmontar a matriz disciplinar da escola e pude observar a construção do conhecimento de maneira transdisciplinar.

Quadro 3: Resumo das atividades do estágio docência 3.

\begin{tabular}{|c|c|}
\hline Atividade de problematização - aula 1 & $\begin{array}{l}\text { Reunimos todos os alunos no pátio da escola para a } \\
\text { apresentação do tema do estágio. Planejamos atividades } \\
\text { práticas e conversamos sobre como esse saberes } \\
\text { contribuirão para o futuro das próximas gerações do povo } \\
\text { Apinajé. As crianças de } 4 \text { a } 11 \text { anos, meninos e meninas, } \\
\text { após a conversa estavam alegres e queriam logo fazer os } \\
\text { artesanatos. Expliquei que é uma atividade das mulheres, } \\
\text { mas que o homem podia fazer naquela semana. }\end{array}$ \\
\hline Atividade prática - aula 2 & $\begin{array}{l}\text { Fomos à mata cortar o olho amarelo do pé de babaçu, pela } \\
\text { manhã. As crianças observaram cada passo da retirada da } \\
\text { palha. No caminho, os alunos se divertiram muito. Tinha } \\
\text { outras palhas parecidas com o babaçu. Eu explicava cada } \\
\text { tipo de palha. Mostrei as diversas flores presentes no } \\
\text { caminho. Logo chegamos ao ribeirão para tomar água. Os } \\
\text { alunos ficaram maravilhados e felizes. Um a um, pegaram } \\
\text { uma fita e fizeram um apito, soprando junto com os } \\
\text { cânticos dos pássaros. O vento batia na palmeira. A } \\
\text { natureza estava feliz se comunicando com o gemido das } \\
\text { descobertas das crianças. Bem longe das disciplinas. } \\
\text { Cortamos palha para cada aluno e retornamos para a aldeia. } \\
\text { As brincadeiras continuaram, as crianças correndo, pisando } \\
\text { na ponta da palha e, assim, chegamos à escola, colocando } \\
\text { os nomes em cada palha. Guardamos para o próximo dia. } \\
\text { Cansados, fomos tomar banho no ribeirão Botica e } \\
\text { lancharmos. No final, fiz o convite para o próximo dia, que } \\
\text { cada aluno trouxesse sua mãe. }\end{array}$ \\
\hline Atividade comunitária - aula 3 & $\begin{array}{l}\text { Chegado o momento do grande dia, reunimos alunos, mães } \\
\text { e comunidade. Apresentei o tema contextual que é muito } \\
\text { importante para nossa sustentabilidade cultural, } \\
\text { econômica, política, ambiental e da linguagem. }\end{array}$ \\
\hline
\end{tabular}




\begin{tabular}{|l|l|}
\hline Atividades prática - aula 4 & $\begin{array}{l}\text { A anciã Maria Amnhák (viúva) foi convidada para } \\
\text { explicar, passo a passo, a confeção da esteira e do abano, } \\
\text { na prática. Ela explicou qual o tamanho da esteira a ser } \\
\text { cortada, para o tipo de ocasião, o espaço entre a palha, o } \\
\text { comprimento, o tempo certo que deve ficar no sol. } \\
\text { Explicou que existem os tipos de trançado e que se deve } \\
\text { separar o meio para poder (kohe) começar a entrançar a } \\
\text { esteira. }\end{array}$ \\
\hline Atividade comunitária - aula 5 & $\begin{array}{l}\text { Os alunos, com auxílio de suas mães, começaram a } \\
\text { confeccionar seu material. Em cerca de duas horas, os } \\
\text { alunos desenvolveram a esteira e uns preferiram } \\
\text { confeccionar o abano. Alguns demonstraram dificuldades, } \\
\text { mas outros não. Foi um momento de união entre mães e } \\
\text { alunos na escola. A escola se fazia comunitária. As pessoas } \\
\text { solicitaram outros momentos como este. }\end{array}$ \\
\hline
\end{tabular}

Fonte: Sheila Maxy.

Foto 2 - Atividade prática.

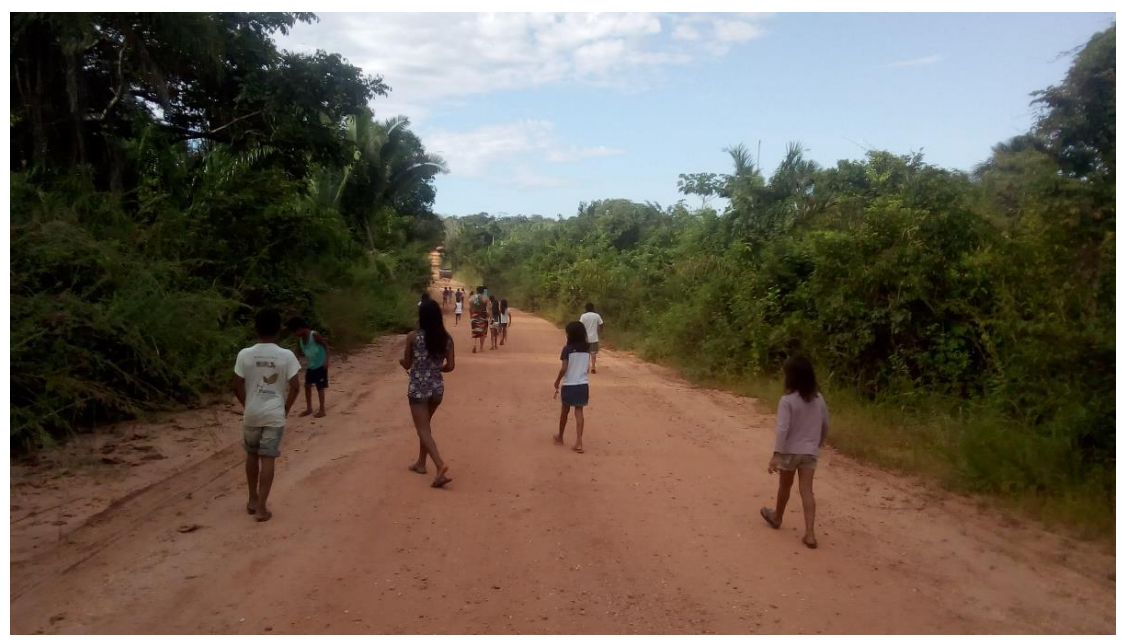

Fonte: Sheila Maxy.

Desde a escolha do tema até a realização do estágio foram vários dias de trabalho. Teve debate e vivenciamos momentos de retomada dos saberes indígenas. Aprendemos sobre esteira e abano, mas também sobre o babaçu e as flores. Aprendemos sobre o território. Foi muito importante para mim e para a comunidade. Foi um lindo trabalho o terceiro estágio. A cada estágio, estou com mais experiência. Outros virão, com mais força, para passar aquilo que já aprendi e para seguir aprendendo. 
Foto 3 - Atividade de esteira e abano.

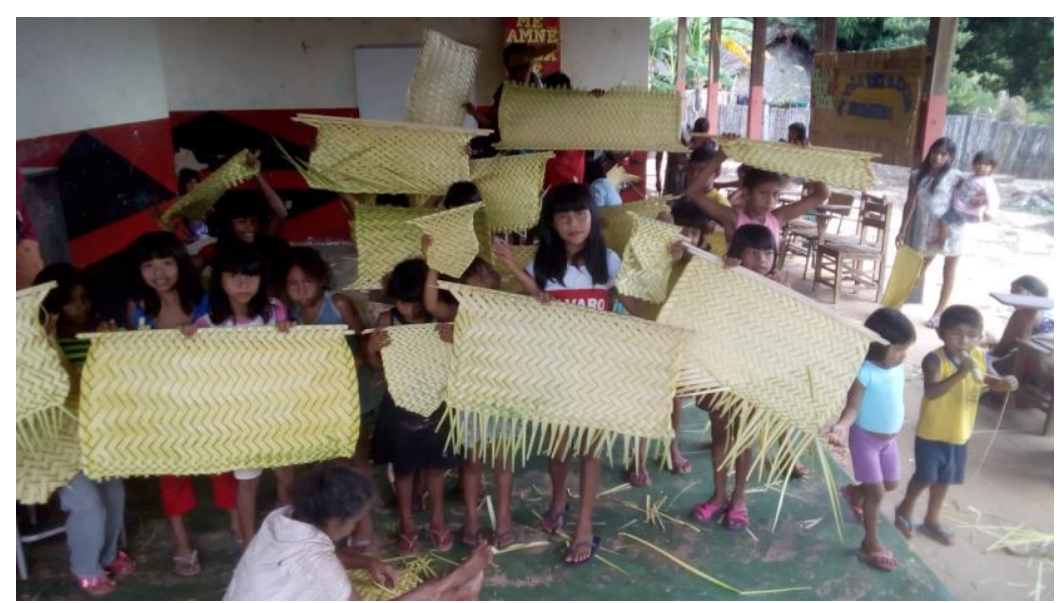

Fonte: Sheila Maxy.

\section{Conclusão}

Percebi, até o momento, a importância do tema contextual para retomar práticas, relações e saberes entre nós, Apinajé. Entendi que o TC deve ser desenvolvido a partir da problematização do mundo e que desta forma o tema terá sentido para a comunidade. Ficou claro também a importância da articulação de atividades de problematização, atividades práticas e atividades comunitárias. Espero melhorar minha compreensão e prática do tema contextual nos próximos estágios.

\section{Referência}

PIMENTEL DA SILVA, Maria do Socorro et al. Projeto Político Pedagógico. Núcleo Takinahaky de Formação Superior Indígena. Universidade Federal de Goiás, 2006.

Submetido em 02 de julho de 2019.

Aceito em 15 de agosto de 2019.

Publicado em 15 de agosto de 2019. 